LUXIÉRNAGA

David Isaí Lara Prieto 


\section{El tiempo óptimo para vivir}

\section{Introducción}

En los tiempos modernos se ha avanzado bastante en temas médicos y de salud. Se están desarrollando cada vez más estas tecnologías en pro de alargar la esperanza de vida de los seres humanos. Pero ¿cuál es el propósito de vivir cada vez más tiempo? ¿es mejor vivir mucho tiempo, aunque en la vejez no se tenga plenitud? ¿es mejor vivir un tiempo corto, pero sin los estragos de las deficiencias que traen la edad y la enfermedad? y aunque no se tenga que sufrir si vives muchos años ise necesita mucho tiempo para vivir una vida plena?

Aquí trataremos de responder esas y otras preguntas. El problema será entonces enfocado al cómo es prudente vivir la vida y a la desvalorización de ésta al verse extendida cada vez más, pero ssería posible que la vida pierda parte de su valor, si cada vez tenemos más tiempo para posponer lo que queremos hacer mientras la tengamos? A primera vista podría parecer que no, porque el tener más tiempo nos facilita el hacer más cosas dentro de este paréntesis, que es el tiempo de vida. Dentro de esto se podría argumentar que el desarrollo humano será más completo si se tiene más tiempo y, consecuente de este, más posibilidades ¿pero estos argumentos serán del todo ciertos?

Por otro lado, se puede decir que, si bien no todos buscaremos un desarrollo humano, dentro del paréntesis corto que es nuestra vida, no sería diferente si tuviéramos más tiempo. Principalmente porque esto no está presente en las metas de la mayoría, siendo estas muy cambiantes entre los miembros de una comunidad. Y aunque se dé el caso en que el individuo sea consciente de lo que sea que se esté buscando calgún día lo podrá encontrar? ¿le bastará con lograr ese objetivo que se propuso como fin para el sentido de su vida o buscará algo que sea imposible de alcanzar? si es verdad que buscamos algo que no podremos alcanzar mientras estemos vivos ien realidad lo que 
buscamos está más allá de nuestra vida terrenal y necesitamos, creer que en morir existe la respuesta? Este será el objetivo de nuestro trabajo, el buscar razones suficientes que fundamenten una respuesta a la pregunta de si es necesario el alargar nuestra vida.

\section{El tiempo óptimo para vivir}

"Sólo que como el niño es un futuro activo, la sociedad al invertir en él garantiza su propio futuro, mientras que a sus ojos el viejo es un muerto a plazo fijo". ${ }^{\text {I }}$ Nuestra pregunta principal es sencilla ¿es necesario vivir cada vez más tiempo? Bueno, esto dependerá de cómo se quiera vivir este periodo de tiempo. Porque de esta pregunta se deducen otras que la condicionan y está enfocada a saber en qué calidad se tiene que vivir durante este tiempo, porque no será lo mismo el vivir hasta los cien años manteniéndote siempre joven, que el vivirlos mientras el periodo final de tu vida lo pasarás en un estado en el que tu cuerpo, y consecuentemente tu mente, no responderán de la misma manera en la que lo hacían durante su juventud.

Antes de entender el problema que puede presentarse en la vejez, se tienen que poner acuerdos que definan, a partir de cuándo, un individuo puede ser llamado "viejo'? Porque no será lo apropiado el determinar de manera arbitraria una edad, a partir de la cual se dejará la plenitud de la vida adulta y se pasará a la vejez, pero ¿no existe de verdad una edad específica a partir de la cual un sujeto pueda ser llamado viejo? A lo largo de los años te puedes dar cuenta que la juventud, y la vejez, es subjetiva y no se presenta de una manera uniforme en todos los individuos.

¿Cómo es entonces la vejez? ¿Cómo se sabe que alguien ya es viejo? Pues bien, como dijo Simone de Beauvoir, existen varios periodos en los que se puede dividir la existencia del hombre común. Se empieza por una etapa primera de desarrollo en la que el individuo busca hacerse de las capacidades necesarias para sobrevivir por su cuenta, esto mientras se ve apoyado por otros que están ya en una etapa adulta y que en la

\footnotetext{
${ }^{1}$ Beauvoir, Simone. (1990). La vejez, Editorial Hermes. México, p. 260.

2 Usaremos el término 'viejo' para hablar de un estado físico, sin denigrar, menospreciar, ni ofender a nadie.
} 
mayoría de los casos son sus padres; se sigue de otra en la que ya se cuenta con las herramientas necesarias para sobrevivir por cuenta propia y en la que se pasará a dejar de ser dependiente de la protección de los adultos que se dedicaban a protegerlo. En esta etapa empezará a vivir una plenitud al deshacerse de las normas que lo regían y desarrollará una personalidad que le será propia y sólo se verá influenciada por lo que él experimente; cuando el cuerpo de éste empiece a deteriorarse con el pasar de los años, necesitará, nuevamente, de verse asistido para sobrevivir y volverá a ese rol en el que depende de los demás para realizar las tareas básicas. A partir de aquí, el individuo sabe que sólo la muerte es lo que le sigue, ya no esperará a convertirse en algo más como lo hace el niño y el adulto. El viejo se sabe impotente al verse limitado con la carga que ahora le presenta su cuerpo decadente y sabe también que la muerte está cerca.

Esta tercera etapa del desarrollo será la que consideremos como la vejez. En esta, el individuo dejó atrás la independencia que tenía al momento de que sus capacidades, principalmente físicas, se ven disminuidas al punto de no poder realizar tareas sencillas con la facilidad de la juventud. Este será el momento en el que el sujeto podrá ser llamado viejo, cuando el cuerpo se vuelve frágil, las dolencias cobran una verdadera importancia y son ya irremediables. A partir de aquí se sabe que el cuerpo declina y pasa a ser impotente en ciertos aspectos.

Sólo analizando la valoración que se le da a las cualidades perdidas con la edad, así, creemos, se podrá dar una respuesta a nuestro problema principal. Para esto, será necesario analizar qué es lo que pasa cuando alguien está en condiciones de ser llamado 'viejo'.

\section{¿Qué es lo que perdemos con la edad?}

En un sentido meramente orgánico, es bien sabido que con la edad el cuerpo del ser humano se ve disminuido en sus capacidades y que se vuelve también más frágil. Con la edad, nos es más difícil el realizar trabajos físicos porque se reduce el vigor muscular, la agudeza auditiva y visual. Así como también se disminuye nuestra destreza y resistencia a 
las condiciones adversas, como son los cambios en la temperatura y la humedad. La fatiga será mayor que en nuestros años mozos y nos veremos impedidos para hacer trabajos donde es importante tener cierto dinamismo. "Estos defectos no quedan compensados por su experiencia, sus calificaciones, su conciencia profesional que son, sin embargo, superiores a las de los jóvenes". ${ }^{3}$ Lo anterior no será lo único que nos aquejará durante la vejez, porque a consecuencia de esto, veremos por parte de la sociedad cierta indiferencia. El principal motivo por el cual los viejos se ven distanciados de la sociedad es porque en esta la utilidad de sus integrantes es la base de su éxito. Así que los viejos, al disminuir o cesar sus acciones productivas, para pasar a un estado de inactividad, en el que esperan de manera paciente el fin, la muerte, se alejan del fin productivo de una sociedad representada por adultos y jóvenes.

Aunque los jóvenes y adultos saben que en algún momento estarán en las mismas condiciones en las que se encuentran los de mayor edad, no tendrán consideración al rechazarlos. Aquí es donde se entiende claramente el problema que podría representar, el ya no contar de manera íntegra con las facultades que brinda la juventud, porque al carecer de utilidad, se pierde el valor humano que le brinda la comunidad a la producción. Y, a final de cuentas, son muertos a corto plazo.

No todo es malo dentro de la vejez, porque al pasar los años, los individuos adquieren características que, en la mayoría de los casos, sólo es probable obtener por medio de la experiencia que traen consigo los años. La regularidad del ritmo, el método, puntualidad, buena voluntad, prudencia, paciencia y el desarrollo de un trabajo bien terminado, son beneficios que se aprecian en la mayoría de la gente que llega a una edad avanzada.

La vejez debe de ser entendida como la disminución en las capacidades generales del organismo. Si un individuo no está en una posición poco favorable en cuanto a sus capacidades físicas o mentales, no puede ser considerado enteramente como viejo. De ahí que se diga que el llegar a la vejez sea relativo.

${ }^{3}$ Beauvoir, Simone, Op. Cit, p. 274. 
La vejez es de especial importancia para el desarrollo de nuestro tema, porque, como se dijo anteriormente, si te llegaran a preguntar ¿cómo es que te gustaría vivir cien años? dándote las opciones de tener un cuerpo joven durante todo este periodo o de un cuerpo que se deteriore como lo es natural, lo normal, sería que eligieras vivir con un cuerpo que se mantenga constante en su jovialidad, salud y capacidades. Pero el problema es que actualmente no existe la tecnología que garantice esta juventud prolongada. Sino que el vivir los cien años, que de hecho es probable, están acompañados por los malestares propios que presenta la vejez como compañeros inseparables. Utilizando esta definición de vejez, trataremos de darle un sentido al tema que nos incumbe.

\section{La problemática de la vejez: ¿una vida sin sentido?}

"Las transformaciones que se han producido en los últimos decenios fuerzan a un cambio de paradigma que tenga en cuenta aspectos que no pueden ya pasarse por alto. Por ejemplo, que el paciente es autónomo y ha de ser escuchado y atender a su consentimiento respecto al tratamiento de sus dolencias, que la gente vive más años y no siempre en condiciones de calidad o dignas $[. ..]{ }^{3}{ }^{4}$ Ahora que sabemos qué es lo que usaremos para definir el llegar a la vejez, tendremos que preguntarnos si estamos dispuestos a aceptar los cambios que vienen con el pasar de los años. Porque claro, el vivir más años no nos garantizará una vida enteramente plena en donde los achaques no nos perjudiquen al punto de preguntarnos si esa es una vida que merece la pena ser vivida. Para esto, tendremos que buscar cuáles serán las características de una 'vida que valga la pena vivir'.

¿Cuándo una vida vale la pena ser vivida? al igual que la definición de vejez, la respuesta se aplicará de manera diferente a cada individuo. Parece ser que, para la mayoría de las personas, la felicidad es un buen fin último, y puede ser considerado como la razón por la cual sería deseable el vivir cada vez más tiempo. Y suena lógico, si

${ }^{4}$ Camps, Victoria. (2005). La voluntad de vivirBarcelona: Editorial Ariel. , p. 151 
lo vez desde este punto, porque si tienes más tiempo para hacer lo que te hace feliz, serás más feliz. El problema se hace presente a medida en que nos damos cuenta que las deficiencias de la vejez podrían afectar esta actividad que nos hace felices. Para poner un ejemplo, pensaremos en un sujeto que dedicó toda su vida al deporte, porque eso lo hacía feliz. Con el pasar de los años, las facultades físicas que poseía se vieron disminuidas a tal punto en el que le fue imposible el seguir practicándolo. A nuestro sujeto le quedan dos opciones; puede cambiar la actividad que realizó durante toda su vida y en la que encontraba la felicidad, por otra, en la que encuentre cierta satisfacción y acorde a sus condiciones actuales; o, puede caer en una negación propia, y perder los deseos de vivir que tenía, ya que la vejez se presentó en él de una manera que le arrebató lo que lo hacía feliz.

Entendiendo esto encontramos el meollo del asunto. Porque, el problema no será a qué dediques tu vida, sino, si estamos dispuestos a dejar de lado aquello que en realidad nos hace felices, al veremos imposibilitados a hacerlo llegado el momento en el que nuestras capacidades ya no nos lo permitan. Incluso, más allá de hacer lo que nos gusta hacer, el vernos negados a hacer actividades básicas con normalidad y el necesitar la ayuda de alguien más puede ser un factor importante a la hora de decidir si queremos vivir tantos años dentro de la incapacidad.

Por cómo se plantea el problema parece ser que existen, principalmente, dos grupos de actividades generales en las que entran actividades más particulares y específicas. Estas son actividades en las que se desarrolla el cuerpo y actividades en las que se desarrolla la mente. Ambas encierran, dentro de sí, actividades más específicas y en las cuales el individuo suele encontrar algo que le produzca felicidad al realizarla. Las divisiones de estos dos grupos principales, no impedirán que el sujeto escoja una mezcla de actividades entre ambos grupos, así como tampoco es necesario que tenga que escoger de ambos grupos, siendo que se puede dedicar enteramente a un sólo grupo. Tendrá alguna actividad en la cual tenga preferencia sobre las demás y de aquí podrá decidir algo que hacer cuando se vea imposibilitado de hacer la de su preferencia. 
Ahora bien, de estos dos grupos de actividades, es como se define, en gran parte, el problema. Porque si se escoge una actividad física, como la principal, sucederá que el sujeto, al verse imposibilitado por un cuerpo debilitado por lo años, no podrá desarrollar más esa actividad que le producía la felicidad. Dependerá de su capacidad para adaptarse a los cambios y de las actividades restantes de su preferencia, el que adopte una nueva actividad. Será lo natural que, si todas las actividades que se interesó en desarrollar fueron siempre relacionadas con el cuerpo y sus capacidades motoras, se le dificultará el encontrar una nueva actividad que le produzca felicidad. Sucederá lo mismo con quien decida desarrollar únicamente actividades que estimulen su mente, porque si llegase a sufrir de alguna enfermedad que disminuya sus capacidades mentales como la memoria y el pensamiento abstracto, también se le dificultaría el encontrar nuevos motivos y actividades que le den felicidad. Principalmente de esto dependerá que queramos seguir viviendo más años, de nuestra capacidad de adaptarnos a nuevas situaciones que nos garanticen una vida feliz.

\section{El objetivo de la ciencia hacia una buena vida.}

Ya que todavía no contamos con la capacidad de desarrollar tecnología que, si bien no nos garantice una mayor cantidad de tiempo viviendo, no estamos tampoco en condiciones de permitirnos vivir, todo el tiempo que estemos aquí, de una manera en la que los deseos de vivir, y ser feliz, no desaparezcan; no debería el ser tomada con mucha seriedad una propuesta de vida que en algún momento creas carente de sentido. Lo ideal será entonces, que pudiéramos vivir la cantidad de años de un hombre viejo mientras conservamos todas las facultades de un cuerpo joven, sin dejar de adquirir la experiencia propia de los años.

Aunque Mercedes Garzón no se cuestiona de manera abierta sobre el tema de la vejez en su texto La ética, habla sobre la responsabilidad moral que tiene la ciencia en cuanto al servir como herramienta para el desarrollo del hombre. 
Esto nos lleva al problema de la responsabilidad moral del científico, quien, además de estar comprometido con la verdad científica, también está inmerso en todas las relaciones de su sociedad: tiene una determinada ideología y moral, por lo que ni los resultados de su investigación ni el empleo de estos se sustraerán a una especie de implicaciones sociales. En consecuencia, debe asumir el papel que desempeña en la sociedad e intentar participar activamente en las relaciones activas al uso y la aplicación de sus descubrimientos, ya que, en última instancia, es responsable de las consecuencias a que éstos den lugar en la sociedad donde vive. $^{5}$

Y es en base a este fin 'útil' de la ciencia en el que se debería fundamentar y lograr la plenitud en la vida de quienes participan de ella dentro de la sociedad. El fin de buscar en la ciencia esta utilidad nos hace pensar que, en las ramas de la medicina, la prolongación de la vida será, ciertamente, más útil si el cuerpo nunca pasara por este proceso de deterioro.

\section{Conclusiones}

En un intento por encontrar una respuesta satisfactoria a qué es la vejez, nos encontramos con la dificultad de definir un proceso biológico que no afecta a todos de la misma manera. La vejez es entendida como el proceso de degeneración de nuestro cuerpo, donde las habilidades desarrolladas, durante las primeras etapas de la vida, junto con varias de las funciones básicas del cuerpo, se ven paleadas por un tiempo que no permite la regeneración de unas ya agotadas funciones corporales. El proceso de envejecer es la incapacidad del cuerpo para encontrar una manera de sustituir las funciones perdidas.

Con esta definición parece que no hacemos más que señalar lo obvio e iluminado a simple vista. Pero, aunque parezca un paso inútil, será necesario demarcar los límites que alcanzará la vejez para un futuro en el que se necesite una respuesta, más sintética, a la pregunta de su definición.

En cuanto a lo que un individuo puede desear para su vida, el decidir en cuanto a la cuestión de las dificultades presentadas en la vejez, debe de ser algo importante. Primeramente, se tiene que decidir si la visión que tenemos de nuestros futuros cuerpos,

${ }^{5}$ Garzón, Mercedes. (1997). La ética. Consejo Nacional para la Cultura y las Artes. México. D. F., p. 49. 
deteriorados, es deseable para después encontrarnos con la dificultad de que, al momento de haber llegado a ese punto, no decidamos arrepentirnos de las decisiones tomadas durante la juventud y adoptemos las características que nos dejaron los años en un intento por aferrarnos a la vida que nos quedó.

Confesar que el decidir durante tu juventud sobre tu futuro incapacitado es una apuesta arriesgada no se aleja mucho de lo que pasa en la mayoría de los casos. Porque, así como antes deseabas estar haciendo otras cosas en el que es tu presente, ahora, no será raro que tus pensamientos sean distintos llegado ese tiempo. Aunque muy probablemente sea por el verte ya envuelto en esa serie de circunstancias. Por lo que, analizando bien las posibilidades y a modo de conclusión del tema, lo deseable sería una vida donde el cuerpo no te presente mayores dificultades a la hora de concentrarnos en las cosas que deberían de ocupar nuestro tiempo. 